\title{
AN INNOVATIVE WAY OF DESIGNING BLENDED LEARNING THROUGH DESIGN-BASED RESEARCH IN HIGHER EDUCATION
}

\author{
Dr. Ahmet Berk USTUN \\ ORCID: 0000-0002-1640-4291 \\ Faculty of Sciences \\ Bartin University \\ Bartin, TURKEY \\ Dr. Monica Walch TRACEY \\ ORCID: 0000-0001-9665-3468 \\ College of Education \\ Wayne State University \\ Detroit, Michigan, USA
}

Received: 24/07/2020 Accepted: 27/08/2020

\begin{abstract}
Within higher education, the use of blended learning (BL) is exponentially increased in the 21 st century, which poses a number of challenges in designing the process of BL for educators. The aim of this designbased research (DBR) study was to assist an inexperienced educator in teaching and designing a BL course in higher education to convert a face-to-face (F2F) course into a BL course. During the design and delivery of the BL course, what appropriate practices were needed to achieve creating an efficient and effective BL course were determined and the educator's reflections on the first experience of teaching the BL course were documented over three iterative design cycles. Mixed methods including learning environment observations, educator interviews, student surveys were employed. The results demonstrated that BL enabled the educator to adopt active learning approaches, engage students in critical thinking and promote the quality of interactive and collaborative learning assignments. Although the educator indicated the time limitation as an obstacle to teach a more efficient BL course, the educator was contented with teaching and designing the BL course and found it useful and supportive overall. Findings were presented and discussed for future studies and implications.
\end{abstract}

Keywords: Cooperative/collaborative learning, interactive learning environments, teaching/learning strategies, improving classroom teaching, blended learning.

\section{INTRODUCTION}

The evolution of internet technology makes instruction online possible, which is seen as significant progress in the learning and teaching process (Chou \& Chou, 2011). Online learning (OL) exceeds the boundary of traditional learning that provides opportunities for distance students to get educated. Also, educators still promote written communication, critical thinking, collaboration, and problem-solving by using, managing or generating flexible, open, and ubiquitous online applications in their online courses (McKeachie \& Svinicki, 2014, p. 233). However, the absence of F2F interactions and communications between an educator and students is one of its inherent hindrances that students are deprived of enough educator support. For instance, students who have a lack of study skills such as self-disciplined have difficulty in maintaining motivation, meeting commitments and managing time in OL (McKeachie \& Svinicki, 2014, p. 302). Due to the drawbacks of OL, a new approach, blended learning (BL) has emerged to alleviate the disadvantages of OL. Garrison and Kanuka (2004) state that BL has massive versatility that offers increased efficient and effective learning experience and enhances meaningful learning outcomes. In this sense, the popularity of BL has increased among most researchers (Chou \& Chou, 2011) in parallel with the adoption of BL has become prevalent in the number of higher education institutions (Garrison \& Vaughan, 2007). 
Although there is an ambiguity in the definition of BL by researchers, the combination of F2F and online instruction is a widely accepted definition of BL (Graham 2006). According to Graham (2006), this perspective in the literature exactly mirrors the historical emergence of BL approaches. In this study, BL is defined as thoughtfully and vigilantly integrating the best features of F2F learning and the best features of OL (Bonk \& Graham, 2006; Garrison \& Kanuka, 2004; Graham, 2013; Osguthorpe \& Graham, 2003). The rigorous and thoughtful integration of OL and F2F means taking advantage of the strengths of them and avoiding weaknesses of them. It is also necessary to achieve the right balance between F2F and OL to take full advantage of BL (Vanslambrouck, Zhu, Lombaerts, Philipsen \& Tondeur, 2018). Garrison \& Kanuka (2004) elucidate how to make this integration by stating that

\begin{abstract}
"the core issue and argument is such that, when we have solid understandings of the properties of the Internet, as well as knowledge of how to effectively integrate Internet technology with the most desirable and valued characteristics of face-to-face learning experiences, a quantum shift occurs in terms of the nature and quality of the educational experience" (p. 97).
\end{abstract}

BL has commonly seen as an effective learning approach (Chou \& Chou, 2011; Graham, 2006; Wu, Tennyson, \& Hsia, 2010) because many studies have shown that BL promotes the acquisition of knowledge and skills in a variety of disciplines (Maza, Lozano, Alarcón, Zuluaga, \& Fadul, 2016). One of the key benefits of $\mathrm{BL}$ is to manage, create, and promote collaborative and interactive learning environments (Graham 2006). Discussions are an essential part of BL to provide high-quality learning experiences that improve performance (Han \& Ellis, 2019). The availability of appropriate various online tools and resources can be adapted to F2F learning in response to constructing a collaborative and interactive $\mathrm{BL}$ environment. The utilization of $\mathrm{BL}$ increases interaction between student-student and educator-student through virtual communities, social networks and computer-supported collaboration if OL technologies are appropriately selected and rigorously integrated into the learning environment. (Geng, Law, \& Niu, 2019; Graham, 2006). Another key benefit of BL is that BL enables students to study at their own pace and allows educators to provide personalized instruction (Shand \& Glassett Farrelly, 2017). For instance, BL provides opportunities for students to acquire additional clarifications about any topics that remain unclear in the F2F setting from each other and the educator (Vanslambrouck et al., 2018). Karaoglan Yilmaz (2020) states that learning analytics can be utilized to design a personalized learning environment that improves students' academic self-efficacy, problem-solving skills, reflective thinking skills and metacognitive awareness in online, BL or flipped classrooms. BL also offers an accessible and flexible learning environment in which students find opportunities to conveniently reach course materials in various ways such as accessing course materials anywhere, anytime. When students are involved in flexible learning activities and interactive learning experience, the possibility of their satisfaction and learning outcome increases. It has been shown in the literature that student satisfaction can be improved by adopting a BL approach (Bradley et al., 2007; Halverson, Graham, Spring, Drysdale, \& Henrie, 2014) and there is a positive and statistically meaningful correlation between interaction and learning outcome in BL (Al-Ani, 2013; Wu et al., 2010).

While BL has commonly been exalted by scholars, significant challenges of designing a BL course such as facilitating students' learning processes incorporating flexibility, fostering an effective learning climate and stimulating interaction have been identified by Boelens, De Wever and Voet (2017). Although it is easy to declare that $\mathrm{BL}$ transforms the learning environment from a traditional classroom setting to an active learning classroom setting, Baehr (2012) indicates that consolidating best practices of F2F and OL is a complex process that requires educators to invest enough time to select and test the right technological resources in accordance with intended tasks, knowledge sharing, activities, and learning outcomes of a particular course. Bilgic and Tuzun (2020) point out that there is an essential need to make a detailed plan to achieve the desired outcomes when teaching an online course or, failing that, OL will end up posing new obstacles that educators and students face. Another challenge might be the insufficiency or absence of institutional support that is related to professional development orientations, institutional policies, technical and pedagogical support, structures and incentives. The findings of the study conducted by Porter, Graham, Spring and Welch (2014) show that educators' technical and pedagogical training offered by institutions 
are significant determinants that optimize the design and implementation of BL and increase the adoption of BL. When taking the challenge of BL into account, it is not a straightforward process to design and implement BL. Kanuka and Garrison (2004) indicate that BL might bring about "daunting challenges" in the design process because of its "implementation with challenge of virtually limitless design possibilities and applicability to so many contexts" (p. 96).

\section{PURPOSE OF THE STUDY}

The process of designing a $\mathrm{BL}$ environment requires educators to take many factors into consideration (Galvis, 2018). The balance between the best features of OL and F2F learning is the major consideration in designing a BL course. Osguthorpe and Graham (2003) identify student characteristics, instructional goals, online resources, and educator background as the points to be paid attention to when finding out an optimal balance in a BL course. Contemplating how to balance, select, prepare and enact instructional method, personalized course content, new tools, assessment strategy, etc. may produce many other challenges educators might encounter while teaching and designing a BL course. This process requires educators to demonstrate their problem-solving skills (Hew \& Cheung, 2014). However, educators' decisions that impede or facilitate their BL adoption regarding the design and implementation of BL have been explored by an insufficient number of studies (Porter \& Graham, 2016). Particularly, a gap that there remains a need to investigate an educator's initial experience in teaching, designing and implementing a BL course in higher education exists in the research literature. The aim of this DBR study research is to find out what practices were needed to assist an educator who was inexperienced in teaching and designing a BL course to successfully design and deliver it in a systematic and holistic manner. The following three research questions were addressed in the study:

1. What practices are associated with making a blended learning course efficient and effective?

2. What are the educator's perceptions about their first experience of teaching a blended learning course?

3. Does the iterative process of this design-based research study improve the effectiveness and efficiency of a blended learning course throughout the semester?

\section{METHOD}

This study followed a DBR method documenting an instructional design effort. Although DBR is defined as "a systematic but flexible methodology aimed to improve educational practices through iterative analysis, design, development, and implementation, based on collaboration among researchers and practitioners in real-world settings, and leading to contextually-sensitive design principles and theories" (Wang and Hannafin, 2005, p. 6), McKenney and Reeves (2014) state that it is not a methodology but "it uses quantitative, qualitative and -probably most often- mixed methods to answer research questions" (p. 133). Multiple sources such as observation, interviews, documents, and reports are used to gather information by using data collection tools (Creswell, 2007). Interviews along with surveys and observations were utilized to gather data in this study to make in-depth and comprehensive analyses and guide the design effort.

\section{Participants}

A purposeful sampling was used in the study because it is a suitable method to gather data for a particular study when researchers seek specific informants who are reflective, articulate, and willing to share their experiences with the interviewer (Morse, $1991 \&$ Tongco, 2007). Identifying the criteria to make purposeful sampling was necessary because prospective participants should meet the specific requirements to be the actual participants (Patton, 1990). Thus, the following criteria were established to determine a suitable participant for the study:

- A participant needs to have a moderate degree of proficiency in utilizing online components, asking questions, supervising students, and provoking a discussion in OL.

- A participant is not reluctant to improve IT capabilities. 
- A participant is not prejudiced against utilizing technology inside and outside the classroom.

- A participant's institution needs to provide the technological and physical infrastructure to deliver an online course.

A Psychology educator who met the selection criteria was determined to be a suitable participant for this study. The educator is a full-time faculty and professor in Psychology. Even though the educator has been teaching F2F undergraduate and graduate level courses, the educator have not taught and designed a BL course. After realizing the potential benefits of this study, the educator agreed to cooperate with the lead researcher to transform a F2F graduate course to a BL course in the Fall term of the academic year 20162017. It was a four credit course and had strict requirements including attending lectures and doing reading assignments. Also, the students who enrolled in this graduate level course was the second participant group. They were eleven students comprising ten female and one male. They fulfilled the criterion as they had a moderate degree of proficiency to attend online instruction. They were able to send e-mails, conduct videoconferences, post threads, etc. If they didn't show enough proficiency, a preliminary meeting was scheduled to prepare them for this BL course. Finally, instructional design experts who worked at The Office for Teaching \& Learning at the research university were recruited to examine the BL course and provide feedback.

\section{Data Collection}

This DBR study applied quantitative and qualitative collection methods. Qualitative data were collected at the three appointed times throughout the research. The schedule of three data collection times was as follows:

- Phase 1: From August 19, 2016 to October 7, 2016

- Phase 2: From October 7, 2016 to November 11, 2016

- Phase 3: From November 11, 2016 to December 16, 2016

During Phase 1, interviews were conducted with the educator and instructional design experts. Understanding of the educator's weaknesses and strengths in utilizing technological tools and grasping the objectives of the course and deliberating over designing and implementing a BL course were the main aims of the educator interview. The BL environment was shaped in accordance with the interview. The designed BL environment was judged by the instructional design experts. According to their suggestions, adjustments in the BL environment were made. After it was seen and approved by the educator, the BL environment was implemented. Besides, the lead researcher observed the educator while the educator was teaching the implemented BL course.

During Phase 2, interviews were conducted with the educator and experts again. The main goals of the educator interview were the investigation of the weaknesses and strengths of the educator's online capabilities, and the determination of what practices were related to creating an efficient and effective BL course. The designed BL environment was reshaped based on the interview. This BL environment was judged by the experts to make adjustments according to their suggestions. After the final version of the BL was seen by students and approved by the educator, it was implemented. In addition to that, the lead researcher observed the educator while the educator was teaching in the redesigned BL course.

During Phase 3, an interview was conducted with the educator to unveil the educator's notions about how, why, and what to manage, select, and use technological resources and processes throughout the term. Revealing the educator's thoughts about the first teaching, designing, and implementing experience of the BL course throughout the semester was the main aim of the interview.

The validated Likert instructional materials motivation survey (Keller, 2010) was used as the collection of quantitative data for the enhancement of utilizing instructional tools and activities at the two appointed times throughout the research. Data collection times were scheduled as follows:

- First instructional materials motivation survey: Fifth week of the term (October 5, 2016)

- Second instructional materials motivation survey: Tenth week of the term (November 9, 2016) 


\section{Data Collection Instrumentation}

The Semi-Structured Interviews validated by experienced faculty in designing and teaching BL courses were developed and conducted to obtain reliable qualitative data from the educator. The observation tool derived from "Seven Principles for Good Practice in Undergraduate Education" written by Chickering and Gamson (1987) was used to help evaluate the efficiency and effectiveness of OL. Particularly, the observation of the BL environment assisted the lead researcher to ascertain what remained concealed in the interviews. The Instructional Materials Motivation Survey (IMMS) created by Keller (1987, 2010), a validated survey instrument consisting of 36 items and using a Likert type scale with 5 choices, was used to determine students' motivational attitudes toward using technological tools and instructional activities. It helped assess the effectiveness of the tools and activities employed in the implemented BL course. The use of data collection instruments through three phases is shown in Figure1.

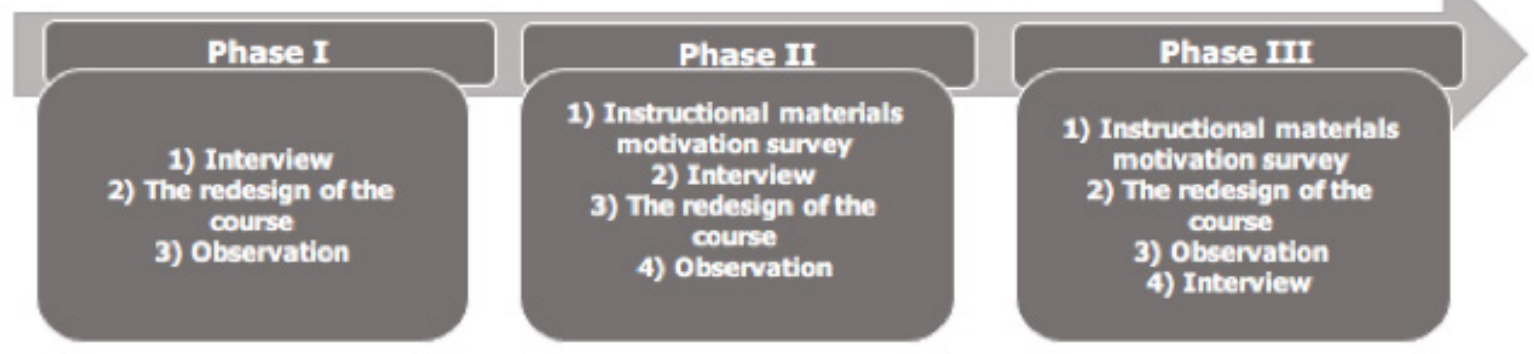

Figure 1. Data collection instruments in each phase

\section{Data Analysis}

The importance of qualitative data analysis was to protect and convey the participants' meanings while analyzing the data (Ruona, 2005). The interviews and observations were rigorously analyzed to extract the meaning and recognize the contradictions between the data collected by both techniques. Therefore, data analysis began at the same time with the first pieces of data being collected and new questions and issues drove further data collection and analysis (Gay, Mills, \& Airasian, 2012; Ruona, 2005). Data analysis was conducted in iterative three stages as follows, (1) reading the data to be acquainted with it and identify possible themes, (2) describing the setting in detail by examining the data and (3) classifying themes derived from pieces of the data (Gay et al., 2012, p. 467). Furthermore, the mean score of the validated survey instrument was computed to help analyze qualitative data.

\section{FINDINGS}

\section{Phase One}

Phase One commenced three weeks prior to the beginning of the Fall term in 2016 and finalized the fourth week of the term. Phase One comprised 1) An educator interview, 2) The redesign of the course, and 3) The observation of the learning environment.

\section{Interview}

The purpose of the interview was to obtain an accurate and deep understanding of the educator's competence, desires and needs for creating a BL course. In order to analyze data, the constant analysis method was used because it was "the explicit coding and analytic procedures" (Glaser, 1965, p. 437) and suitable technique to extract meaning from the data. The lead researcher and two doctoral students studying in the Learning Design and Technology analyzed the interview to secure coding reliability and discover all implicit and explicit themes from the raw data. Three themes, illustrated in Table 1, emerged from the analyses: prior experience, motivation to change and expectation. Respectively, the first theme refers to the educator's former experiences with utilizing technological activities, resources or tools. The second theme refers to 
the educator's desire to transform a F2F course to a BL course. The third theme refers to the educator's expectations of teaching a BL course.

Table 1. Summary of Themes from Initial Interview Result

\begin{tabular}{|c|c|}
\hline Emerging Themes & Sample interview comments \\
\hline \multirow[t]{3}{*}{ Prior experience } & "I can go into blackboard and I can post things" \\
\hline & $\begin{array}{l}\text { "I've been old school...I haven't really done much besides just giving them } \\
\text { links to articles and then we discuss them in class" }\end{array}$ \\
\hline & $\begin{array}{l}\text { "I'm not using technology really. Besides, in this class, I sometimes use } \\
\text { PowerPoints and readings online. That's all." }\end{array}$ \\
\hline \multirow[t]{2}{*}{ Motivation to change } & $\begin{array}{l}\text { "I don't think I can make a statement about overall what l'd like to use. I just } \\
\text { think I will" }\end{array}$ \\
\hline & $\begin{array}{l}\text { "We just work together to come up with some enhancements or the way these } \\
\text { classes run because like I said it's just been run like a classic old school" }\end{array}$ \\
\hline \multirow[t]{3}{*}{ Expectation } & $\begin{array}{l}\text { "I just want it (blended learning) to be interesting for the students. I want it to } \\
\text { be more stimulating and not the same routine all the time." }\end{array}$ \\
\hline & $\begin{array}{l}\text { "Maybe there's a better way for them (students) to show what they learned } \\
\text { than just writing a paper." }\end{array}$ \\
\hline & $\begin{array}{l}\text { "what I'm thinking is going to happen it's going to make them (students) } \\
\text { happier and more it will be more applied more relevant." }\end{array}$ \\
\hline
\end{tabular}

\section{Redesign of the Course}

Converting the traditional F2F learning course to an optimal BL course was the process of redesigning the course that contained converting the syllabus, designing a course Blackboard site and creating instructional activities.

Syllabus. The educator and the lead researcher updated the conventional course syllabus to have the combination of F2F and OL environments reflected in the syllabus via the F2F meetings along with a total of 32 email correspondences. The F2F elements of the course were tightly interwoven with the online elements of the course in the updated syllabus that contained (1) the major revision of the requirements, office hours, course schedule, attendance policy, grading policy, and (2) providing online communication guidelines and new learning activities. For instance, attendance at each F2F class meeting with the expectations such as the interactive discussion on in-depth knowledge of assigned readings and online participation with the expectations such as the number and quality of your discussion posts were clearly indicated in the updated syllabus.

The Course Blackboard Site. The educator designed the course Blackboard site together with the lead researcher in order to provide the online instructional materials that were previously delivered during F2F seat time and a variety of supplemental tools that promoted F2F teaching and facilitated learning. Also, we advertently designed a well-organized and straightforward site that facilitated the preparation, delivery, editing of the course content for the educator and made usability and accessibility of the course content, materials and tools easier for the students. A syllabus, course content, grade book, calendar, announcements, discussions and assignments were fundamental tools to benefit from the features of the course Blackboard site.

Making course materials available, activating the announcement feature and implementing the "Grade Center" were three example tasks outweighing other tasks to demonstrate how to design the course Blackboard site. First, the links for reading materials including articles, reports, and case scenarios and readings assignments were uploaded and delivered through the site to let the students break the chains of traditional learning such as time and location limitations. Second, the main aim of using the announcement tool was to give the students timely notice of critical information for their success. the "Grade Center" was implemented because it was a convenient feature to collect the assignments, manage the grades, give feedback. 
Instructional Activities. Online discussions and online quizzes were two instructional activities to increase communication between the students and educator, promote student interactions and improve self-paced learning. For the first instructional activity, the Blackboard Groups feature in the course Blackboard site was set up for small group discussions that contained multiple forums where a group of students discussed the assigned topics. This activity helped students undertake responsibility for their learning and promoted interaction between themselves. It also enabled the educator to monitor the students' participation, thoughts and reflections upon the assigned readings and to get involved in any group discussions when the group encountered a confusing issue about a course topic. For instance, the educator gave feedback on a thread when a group needed as follows:

"remind me to comment in the class about personal therapy notes and gifts from clients... and anything else that I comment on in my comments back to you guys. When you have specific unanswered questions, just email or call me directly."

Another instructional activity was online quizzes consisting of open-ended questions that sought the students' detailed answers to demonstrate their deep understanding of the course topics. It was a suitable way for the educator to assess each student's reading comprehension and to provide detailed feedback if needed.

\section{Observation of the Learning Environment}

The lead researcher observed the BL environment by utilizing the observation tool while the educator was teaching. The tool was a useful scheme to assess the educator's weaknesses and strengths of teaching the BL course in an efficient and effective way. For the next phase of the study, the observation data were considered to enhance the BL environment as presented in Table 2.

Table 2. Summary of Observation of Learning Environment for Phase One

\begin{tabular}{|c|c|}
\hline \multicolumn{2}{|c|}{ Phase One of Case } \\
\hline $\begin{array}{l}\text { Feedback for } \\
\text { the Educator }\end{array}$ & The Educator \\
\hline \multirow[t]{17}{*}{ Strengths } & - The educator updated the course syllabus in accordance with the BL course. It provided \\
\hline & - Expectations and requirements for due dates of assignments, course interactions and exams \\
\hline & - Netiquette guidelines for online communications \\
\hline & - Explanation of course learning activities, assessments and goals \\
\hline & - Clear criteria for assignment grading \\
\hline & - The explicit and detailed course schedule \\
\hline & - The educator created a positive class atmosphere for learning \\
\hline & - The educator provided interaction space for groups \\
\hline & - The educator provided collaborative learning activities \\
\hline & $\begin{array}{l}\text { - The educator created a well-organized and straightforward course Blackboard site providing easily } \\
\text { accessible learning materials, organized content, easy navigation and free of errors and dead links }\end{array}$ \\
\hline & - The educator provided clear, specific and positive feedback that focused on observable behavior \\
\hline & - The educator allowed peer-to-peer collaboration and responded to students' emails \\
\hline & - The educator used different assessment tools \\
\hline & - The educator provided supplemental online materials \\
\hline & - The educator drew students' attention to the main ideas \\
\hline & - The educator assigned students with thinking, talking, and writing about their learning \\
\hline & - The educator prevented particular students from dominating discussions \\
\hline
\end{tabular}




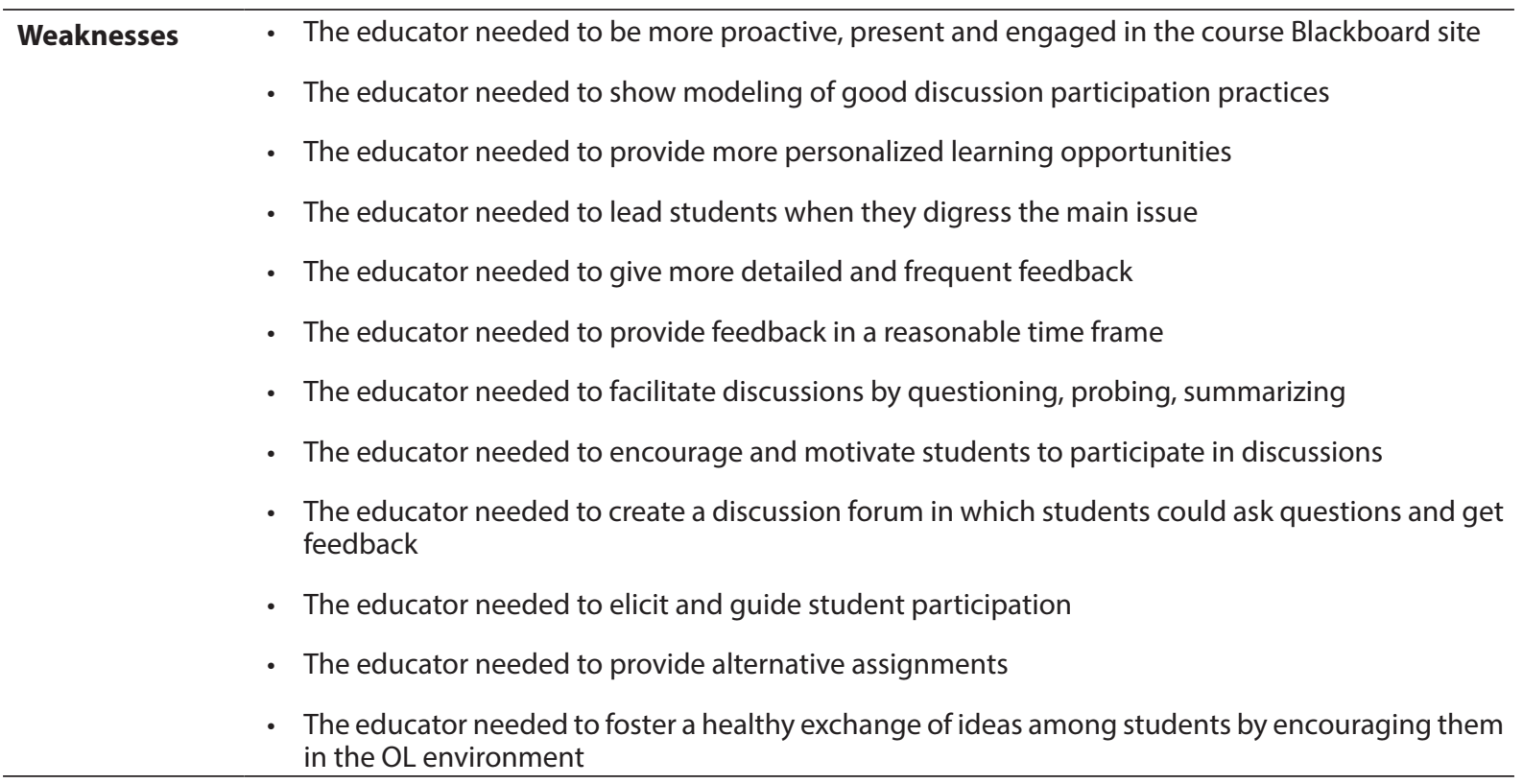

\section{Phase Two}

Phase Two occurred between the fourth week and the ninth week, a five-week period in the term. Phase Two consisted of 4) The first student instructional materials motivation survey, 2) An educator interview, 3) The redesign of the course and 4) Observation of the learning environment

\section{Instructional Materials Motivation Survey}

The first student IMMS (Keller, 2010) was administered by the lead researcher in the 5 th week of the term to find out students' opinions of using the instructional activities and tools. Their opinions helped determine whether utilizing the activities and tools were needed to change in the BL environment. The survey was completed by eleven students.

Reliability is the "degree to which evidence and theory support the interpretation of test scores entailed by proposed uses of tests" (Gall, Borg \& Gall, 1996, p. 191) and George and Mallery (2003) state that ${ }_{-}<.5$ - Unacceptable, ${ }_{-}>.5$ - Poor, _ $>.6$ - Questionable, ${ }_{-}>.7-$ Acceptable, $_{-}>.8$ - Good, and $\_>$ .9 - Excellent (p. 231) are the minimum requirements to ascertain the level of internal reliability. Internal consistency reliability was found as .873 according to the SPSS analysis. Internal consistency reliability of the items showed a good value in the first student IMMS .

Keller (2010) points out that the highest score on the IMMS is 180 and the minimum score is 36 with a midpoint of 108. Eleven students took the survey. The students $(n=11)$ had a mean score of 117 (3.25 out of 5). Yurdakul (2011) asserts that in order to interpret the findings from data analysis, the arithmetic average between " $5,00-3,68$ ", "3,67 - 2,34" and " $2,33-1,00$ " score range respectively refers to a high, moderate and low. Therefore, the score of 117 (3.25 out of 5) demonstrated that students were moderately satisfied with the utilization of instructional tools and activities and implied that they demonstrate a positive attitude towards using instructional materials in the BL environment in the fifth week of the term.

\section{Interview}

The purpose of the interview was to uncover the educator's weaknesses and strengths and assess whether the instructional activities were successful practices in the learning environment. The method of the previous phase was practiced for analyzing the interview. Six themes including motivation to change, benefit, expectation, ambiguity/concern, limitation and resistance emerged from the analysis of the interview as presented in Table 3. "Motivation to change" refers to what motivated the educator to transform the F2F course into the BL course. "Benefit" refers to if the educator obtained the advantage of teaching the BL course. "Expectation" 
refers to what the educator expected while teaching the BL course. "Ambiguity/concern" refers to whether the educator encountered any challenges while teaching and designing the BL course. "Limitation" refers to whether the educator had difficulty in teaching the desired BL course because of the educator's limitations. "Resistance" refers to whether the educator was reluctant to teach the BL course.

Table 3. Summary of Design Improvement Interview Result for Phase Two

\begin{tabular}{|c|c|}
\hline Emerging Themes & Sample interview comments \\
\hline \multirow[t]{3}{*}{ Motivation to change } & $\begin{array}{l}\text { "Your help in accentuating the utility of my materials has been great like I like the online stuff } \\
\text { you know I like having them because I had too much material for the class. I like them doing } \\
\text { that part online and then I don't have to cover it in class, and it gets them stimulated and } \\
\text { thinking about that. }\end{array}$ \\
\hline & I like the group contribution to a document. I like that a lot." \\
\hline & "I like group contribution to a document." \\
\hline \multirow[t]{3}{*}{ Benefit } & $\begin{array}{l}\text { "It (blended learning) made them (students) accountable...I think ultimately they learn a little } \\
\text { bit better because they're held a little more accountable for the online discussion board." }\end{array}$ \\
\hline & $\begin{array}{l}\text { "That's (participation) a positive for the online. Everybody has to chime in..... in class I don't } \\
\text { get as much direct participation because there just isn't time and not everybody is comfort- } \\
\text { able in that format." }\end{array}$ \\
\hline & $\begin{array}{l}\text { "You have facilitated some nice enhancements to my materials to make them have better } \\
\text { utility for instruction." }\end{array}$ \\
\hline Expectation & $\begin{array}{l}\text { "I anticipate them (learning activities) being a really neat way for them to put their materials all } \\
\text { together to look at it and reflect its collaborative in the sense that everybody gets to see each } \\
\text { other's responses and then we can do a better visual comparison." }\end{array}$ \\
\hline \multirow[t]{3}{*}{ Ambiguity/ Concern } & $\begin{array}{l}\text { "There'd be like six, seven, eight different files that I have to look in and I couldn't follow the } \\
\text { thread. I got it well enough, but I haven't done this and so but just some of them I lose the } \\
\text { thread of what they're talking about." }\end{array}$ \\
\hline & "Discussion board takes a little bit of time to figure out where it is" \\
\hline & "I didn't quite figure out how to do the grading on the Blackboard but that's me" \\
\hline \multirow[t]{2}{*}{ Limitation } & $\begin{array}{l}\text { "I would go through and make comments. I honestly don't have time for it. So, I would go } \\
\text { through and scan and make token comments... I was reading and I did see some interesting } \\
\text { things" }\end{array}$ \\
\hline & "I could spend more time I probably didn't do a good enough job." \\
\hline Resistance & "I'm not that impressed by the online stuff" \\
\hline
\end{tabular}

\section{Redesign of the Course}

The educator and the lead researcher jointly strove to foster the course Blackboard site to increase its efficiency and effectiveness by modifying the instructional activities and course site.

The Course Blackboard Site. The well-organized and straightforward design of the course Blackboard site was kept in the second phase. This layout facilitated the delivery and utilization of the instructional materials and a variety of supplemental tools. The use of the site was also a convenient way to make rapid changes as needed. For instance, there were several links to the reading assignments provided in the syllabus. However, some of them were not working because of any longer availability of websites, changes in the URL structure of websites or moving websites without adding URL redirection. This issue was resolved easily by providing the renewed links and announcing the availability of new links on the Blackboard site.

Instructional Activities. In the previous phase, online discussions and online quizzes were created as instructional activities. However, the online discussion activity was not going well as intended because the discussion questions looked for only factual information that could be found in direct quotations from the assigned readings. The questions were modified to allow the students to show their higher-order thinking skills like interpretation, synthesis, or analysis. Also, the educator spent more time in the OL environment to be informative, motivating and encouraging. These modifications enabled the students to be active 
knowledge seekers and participate in thoughtful and in-depth discussions. The educator's quotes from different discussions are below as evidence.

\section{"discussion looking good this week! liking reading your thoughts and what you are digesting." \\ "Thanks for the insightful sharing of personal info, everyone. you guys are getting at some really good issues."}

Observation of the Learning Environment. The lead researcher utilized the same observation. Although the educator had weaknesses in efficiently and effectively teaching the BL course, the strengths of the educator were heightened. The findings of the observation in terms of what changed in the strengths and weaknesses of the educator are indicated in Table 4. For the next phase of the study, the data were taken into account for enhancement in the BL environment

Table 4. Summary of Observation of Learning Environment for Phase Two

\begin{tabular}{|c|c|}
\hline \multicolumn{2}{|c|}{ Phase Two of the Case } \\
\hline $\begin{array}{l}\text { Feedback for the } \\
\text { Educator }\end{array}$ & The Educator \\
\hline \multirow[t]{12}{*}{ Strengths } & $\begin{array}{l}\text { The educator fostered a healthy exchange of ideas among students by encouraging them in the } \\
\text { OL environment }\end{array}$ \\
\hline & $\begin{array}{l}\text { - The educator strove to enhance the navigational skills and provided simply graspable } \\
\text { navigational instructions }\end{array}$ \\
\hline & - The educator asked challenging questions prompting students to think more deeply \\
\hline & $\begin{array}{l}\text { - The educator provided an announcement area where students received important up-to- } \\
\text { date course information }\end{array}$ \\
\hline & - The educator conveyed the aim of the assignments \\
\hline & - The educator led students when they digress the main issue \\
\hline & $\begin{array}{l}\text { - The educator presented divergent viewpoints by making distinctions between fact and } \\
\text { opinion }\end{array}$ \\
\hline & The educator provided more constructive and informative feedback \\
\hline & - The educator asked critical questions about course activities and assignments \\
\hline & - The educator provided feedback in a reasonable time frame \\
\hline & - The educator needed to elicit and guide student participation \\
\hline & - The educator facilitated discussions by questioning, probing, summarizing \\
\hline \multirow[t]{6}{*}{ Weaknesses } & $\begin{array}{l}\text { - The educator needed to be more proactive, present and engaged in the course Blackboard } \\
\text { site }\end{array}$ \\
\hline & - The educator needed to show modeling of good discussion participation practices \\
\hline & - The educator needed to provide more personalized learning opportunities for students \\
\hline & - The educator needed to give more detailed and frequent feedback \\
\hline & $\begin{array}{l}\text { - The educator needed to open a discussion forum in which students could ask questions and } \\
\text { get feedback }\end{array}$ \\
\hline & - The educator needed to provide alternative assignments \\
\hline
\end{tabular}

\section{Phase Three}

Phase Three occurred between the ninth week and at the end of the fourteenth week, a five-week period in the term. Phase Three consisted of 1) The second student instructional materials motivation survey, 2) The redesign of the course, 3) Observation of the learning environment and 4) An educator interview. 


\section{Instructional Materials Motivation Survey}

The second student IMMS (Keller, 2010) was administered by the lead researcher in the 10th week of the term to find out students' opinions of utilizing the instructional tools and activities. Their opinions were considered to ascertain if using instructional activities and tools were needed to change in the BL environment. Eleven students agreed to complete the survey.

According to the SPSS analysis of the second student IMMS, internal consistency reliability was found as .901. Internal consistency of the items showed a good value in the second IMMS. The students $(\mathrm{n}=11)$ got a mean score of 114.8 (3.19 out of 5). Yurdakul (2011) asserts that in order to interpret the findings from data analysis, the arithmetic average between " $5,00-3,68$ ", "3,67 - 2,34" and "2,33 - 1,00" score range respectively refers to a high, moderate and low. Therefore, the score of 114.8 (3.19 out of 5) demonstrated that students were moderately satisfied with the utilization of instructional tools and activities and implied that they demonstrated a positive attitude towards using instructional materials in the BL environment in the 10 th week of the term.

\section{Redesign of the Course}

Redesign of the course including the course Blackboard site and instructional activities was to enhance the efficiency and effectiveness of the BL course.

The Course Blackboard Site. The educator continued to do online discussions, deliver course content, make announcements, comment on student assignments, grade quizzes and use calendar through the course Blackboard site. Also, the same design of the site was preserved.

Instructional Activities. A new instructional activity was added to increase interactions between studentstudent and student-educator and improve collaboration among students in this phase. The educator assigned the students with solving two different case studies by experiencing real-life learning. Groups of students consisting of two to three students had to make in-depth investigations such as interviewing with teachers and an administrator, analyzing official documents to meet the clear requirements of cases. All groups of students convened in the prepared Google Documents to concisely write their findings on topics being addressed in each case. The use of the Google Documents enabled them to scrutinize the findings of other groups and to synchronously or asynchronously discuss, compare and assess any resemblance and discrepancy between their findings. These documents also assisted the educator to guide the students in terms of any groups that stayed back from other groups, needed additional support or advanced toward solving their cases. In addition to creating a new instructional activity, the educator devoted more time to be available in the OL environment, which increased the students' activities, interactions and learning efforts overall.

\section{Observation of the Learning Environment}

The educator exhibited a lack of some essential competencies while teaching the BL course and what changed in the educator's strengths and weaknesses was found by using the observation tool. The educator provided alternative assignment options that personalized student learning and required the students to gather, synthesize, and analyze information to solve problems. Also, although the learning environment was conducive to student learning in terms of exchanging ideas and sharing experiences among students in the previous phase, their collaboration and cooperation exponentially increased by means of drawing advantage of the alternative learning activities. However, the educator's efforts to be present in the course Blackboard site and to be a role model for the students to show how good discussion participation should be were not enough even if there was an explicit increase in the educator's availability in OL. Besides, the students were deprived of a discussion forum in which they could ask questions and receive the educator and peer feedback about course content and activities. 


\section{Interview}

The educator's reflection on teaching a BL course, specifically if BL was an efficient and effective learning environment and if using technological resources was easy to employ in the BL course was revealed through the final interview. The interview was analyzed by using the same techniques employed in previous phases. Five themes including motivation to change, benefit, ambiguity/concern, limitation and resistance emerged from the analysis of the interview as presented in Table 5. "Motivation to change" refers to the educator's desire to convert the classical learning course into the BL course. "Benefit" refers to if the educator benefitted from the advantage of teaching the BL course. "Ambiguity/concern" refers to any difficulties the educator encountered during teaching the BL course. "Limitation" refers to the educator's own restrictions that resulted in ineffectively teaching the BL course. "Resistance" refers to any reason if the educator was reluctant to teach the BL course.

Table 5. Summary of Educator Experience Evaluation Interview Result for Phase Three

\section{Emerging Themes Sample interview comments}

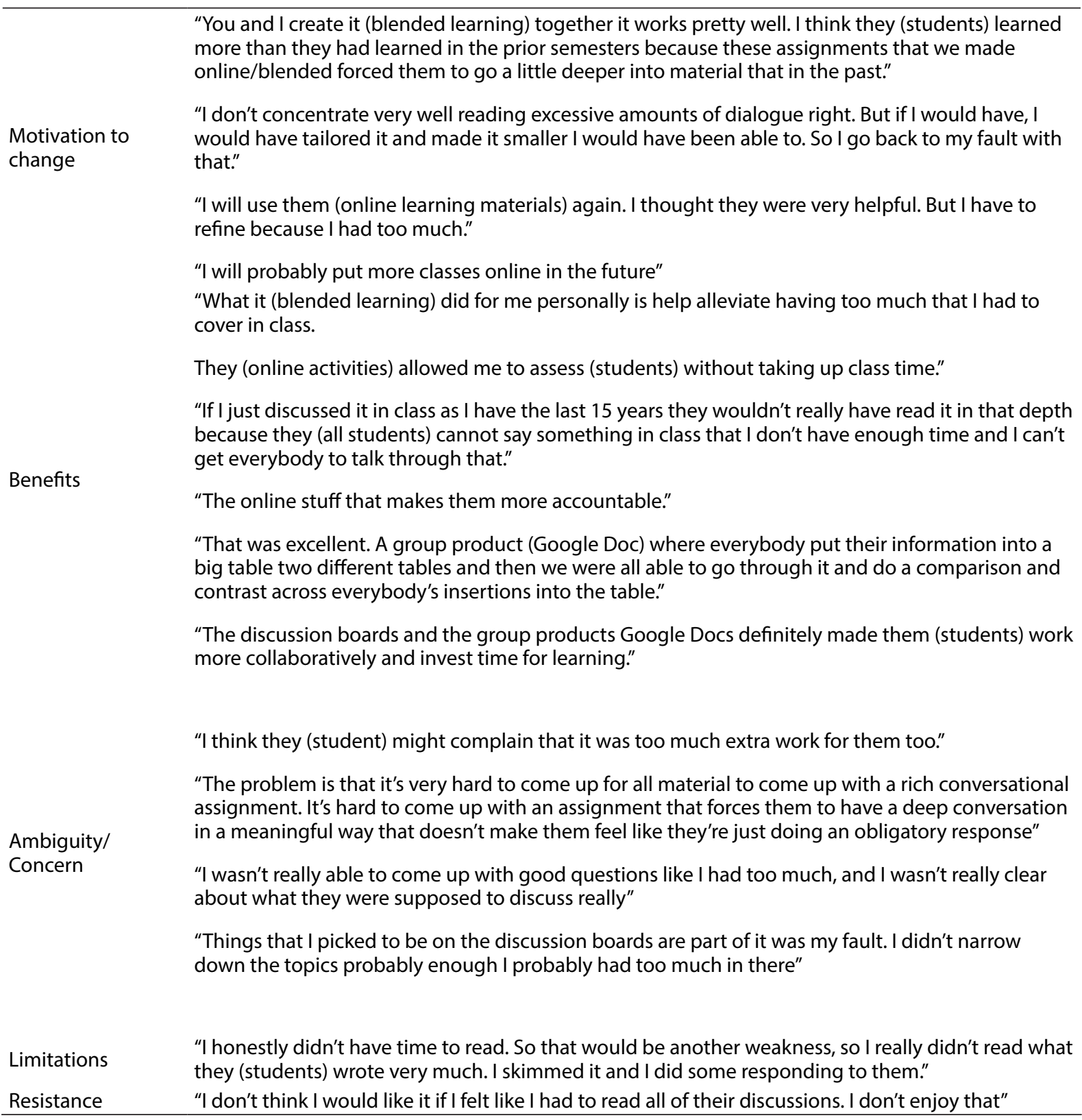




\section{DISCUSSION}

The first research question sought to find out what practices are associated with making a BL course efficient and effective. Creating a BL course requires designers to combine the best features of OL and the best features of F2F learning by considering the student characteristics, educator background, instructional goals, and online resources (Osguthorpe \& Graham, 2003). We began the redesign of the course syllabus by determining and combining the best practices of online and F2F learning. We focused on the educator's prior experiences, particular goals of the course, availability of appropriate technological resources and student characteristics. Converting the traditional course into the BL course, gave a chance to establish a strong rapport with the educator and determine the educator's weaknesses and strengths in teaching a BL course. For instance, the educator stated limited prior experience of the use of technological processes and resources that "I've been old school...I haven't really done much besides just giving them links to articles and then we discuss them in class".

The educator benefited from the use of the course Blackboard site because of the requirements for intense reading assignments. The site provided the means to deliver reading materials online, manage course content easily and mitigate evaluating the assignments and giving feedback on them. BL has been cited as a collaborative and interactive learning environment where students become active participants in their own knowledge construction (Deslauriers, Schelew, \& Wieman, 2011; Graham 2006). Also, Baturay and Toker (2019) express that online collaborative learning activities can be utilized to facilitate student interactions and increase information sharing among students. In this sense, the course Blackboard site enabled the educator to adopt active learning approaches such as discussion activities that engaged the students in critical thinking and promoted collaboration among them. The educator stated that "what I require them (students) to do with the online discussions they definitely had to be active knowledge seekers. They couldn't just passively read the information and then sit back and not really talk in class and I think it encouraged them to work collaboratively with their classmates". The educator implied the effectiveness of the discussion board activities by stating "I think ultimately they learn a little bit better because they're held a little more accountable for the online discussion board". Similarly, Yilmaz (2016) indicates that active learning strategies promote students' participation in virtual learning activities, which results in the enhancement of the learning process and results. Besides, Hosseinpour, Biria and Rezvani (2019) reveal that BL through utilizing Edmodo mobile application enables students to collaboratively work in writing class and therefore, they enhanced their writing skills statistically better than students who are in the traditional classroom setting. They also reveal that most students indicate the effectiveness, helpfulness and attractiveness of learning activities offered in the BL class.

BL has the potential to offer a rich, effective and collaborative learning experience (Garrison \& Kanuka 2004; Picciano 2009). The utilization of Google Documents exponentially increased the quality of interactive and collaborative learning assignments. The educator stated that "Better than my expectation was the group product documents, the Google documents". The use of Google Docs enabled the educator to lead the students to make progress on solving their case studies and motivate them to work collaboratively and productively. The educator stated that "The group products, Google Docs, definitively made them work more collaboratively and invest time for learning". This aligns with the study conducted by Isiguzel (2014) who uncover that BL offers plenty of opportunities such as collaborative learning activities that increase students' motivation in the foreign language classes according to the findings. Zioga and Bikos (2020) investigate the effects of using Google Documents as an online collaborative learning tool on writing skills and found that collaborative writings provide constant feedback from peers and teachers, which helps students enhance their critical and conceptual ability. Besides, Azodi and Lotfi (2020) find that online collaborative tasks on writing performance positively contribute to the enhancement of students' cognitive development and motivate them to strive to overcome various problems they face through the learning process.

The second research question sought to reveal the educator's perceptions of teaching the BL course. The educator pointed out that the limitation of time was an obstacle in teaching the BL course. This aligns with the study conducted by Mozelius and Rydell (2017) who reveal that educators' one of the major challenges for implementing BL courses is a shortage of time. In spite of the time constraint, the educator was very satisfied with teaching the BL course and found the designed BL course useful and overall supportive as indicated in the statement "my overall perception is that it was helpful in alleviating too much in class... the version of a blended learning course you and I create it together it works pretty well... better than my expectation." 
The educator highlighted four benefits of teaching the BL course. First, improved learning was emphasized: "I think they learned more than they had learned in the prior semester". It coincides with the study conducted by Hoic-Bozic, Mornar and Boticki (2009) that shows students who took the course in the BL manner achieved academically higher scores than those who previously took the course taught in the traditional manner. Second, the educator stressed the availability of varied assessment practices: "they [online learning activities] allowed me to assess without taking up class time". Valuable information can be extracted from student interactions to assess student progress in the inclusive BL course (Donnelly, 2010). Third, active learning strategies can be utilized to involve students in group activities and encourage them to contribute to knowledge construction in a BL approach (Garrison \& Kanuka, 2004; Picciano, 2013). Being an active learner was emphasized by the educator stating that "they definitely had to be active knowledge seekers. They couldn't just passively read the information and sit back in class... They are accountable more, the online stuff makes them more accountable". In accordance with that, Maza et al. (2016) found as a result of their study that being an active learner in a flexible BL environment facilitates achieving the target competencies and improves learning for students who even feel contented and in a learning environment in which their educator is a transmitter of knowledge and they passively absorb information and knowledge. Finally, BL has widely been considered as an alternative and effective learning (Chou \& Chou, 2011; Wu et al., 2010). The educator highlighted BL as a supplementary teaching environment by stating that "what it did for me personally is that help alleviate having too much that I had to cover...I could accomplish a similar thing in class but it just sucks up more time and they would never go as deep".

The study was conducted by Geng et al. (2019) who compared a BL course with a nonBL course and found that BL facilitates learning through increasing the sense of engagement and interaction. The educator appreciated the use of Google Docs that promoted student learning through rich peer discussions under the educator's guidance in the BL course. The educator stated that Google Docs was a highly useful collaboration tool to support learning activities, helped shift from a passive teaching style to an active teaching style and encouraged students to embrace deep learning by stating "That was excellent... A group product where everybody put their information into two big different tables and then we were all able to go through it and do a compare and contrast across everybody's insertions into the table". Similarly, Yilmaz, Karaoglan Yilmaz and Kilic Cakmak (2017) reveal that interactive learning tools enable students to collaboratively work with each other and the increase of collaboration enhances their perceptions of social presence in the learning environment.

Ocak (2011) asserts that technical issues and lack of time are barriers that prevent educators from designing and teaching a BL course. The lead researcher closely worked with the educator to design and implement the BL course and provided technical support as needed. Therefore, the educator didn't experience any unresolved technical problems. Even if the educator did not cooperate with the lead researcher and get help for technical issues, most universities in the United States have technology support services to quickly solve such technical problems the educator encountered while teaching the BL course. However, the educator explicitly implied that the shortage of time hampered efficiently teach the BL course by stating "I could spend more time I probably didn't do a good enough job," "I don't have as much time available to spend on the discussion board". This aligns with the study conducted by Napier, Dekhane, and Smith (2011) who revealed that educators who design and teach a BL course possibly encounter a time challenge. Another study conducted by Ibrahim and Nat (2019) found that the design and implementation of a BL course requires a time commitment that negatively influences educators' motivation for creating a BL environment.

The last research question examined if the iterative process of this DBR study improves the efficiency and effectiveness of a BL course throughout the term. The process of three iterative design cycles helped extend and create knowledge about design principles (Reinholz, 2017; The Design-Based Research Collective, 2003). Iteratively analyzing, designing, implementing, and redesigning the BL environment allowed the designers to make an in-depth investigation and gain a comprehensive understanding of what, why and how learning practices worked in the learning environment. Each design cycle systematically refined and improved the previous design of the BL course (Wang \& Hannafin, 2005) that promoted the quality of the BL course. The design of the effective and efficient BL course was achieved through assisting and cooperating with the educator and these refinements of the learning environment in a systematic but flexible manner. After determining the lack of depth in the discussion questions, where students provided only 
factual information, the educator modified questions requiring students to show their higher-order thinking skills such as analysis, synthesis, or interpretation in the second phase. This modification made a significant difference in stimulating the sharing of experiences among the students and promoting a healthy exchange of ideas. It is possible to design and implement the desired BL environment by finding practical solutions when facing real-world problems through iterative refinements of learning activities and enhancements of the learning process.

Dynamic Google Docs and interactive discussion board activities were added to maximize the efficiency and effectiveness of interactive learning activities. Google Documents were employed in response to the educator's demand in using a practical and useful interactive and collaboration tool. Also, the educator's competencies improved in terms of teaching the BL course through each subsequent cycle to provide personalized tasks through alternative assignment options, engage the students in collaborative learning activities under the educator's guidance and support and respond to students' diverse learning inquiries. These are the vital roles in teaching a BL course such as coaching, mentoring and counseling to establish a highly effective and meaningful learning experience (Bonk, Kim, \& Zeng, 2006, p.564). DBR was carried out by Jepchumba and Gaceri (2013) who revealed that educators' teaching practices, professional development regarding selecting and using technologies and students' learning experiences are considerably improved in the BL environment.

\section{IMPLICATIONS FOR PRACTICE}

This study indicated that BL is an effective approach if the optimal balance between online and F2F learning is built. The educator who teaches a BL course takes a role in the plan, design and development of BL and the related literature highlights that this role is as critical as consideration of students' role in the learning (Hew $\&$ Cheung, 2014). The importance of the research was to explore the wide range of designed innovations and an optimal method for educators to plan, teach and enact a BL course. We discussed creating a BL course in a flexible and holistic way in terms of what steps educators should take, how to manage, use, and select suitable technological resources and processes, what obstacles they may encounter, and how to design, implement, evaluate and redesign a BL course. Instructional designers might find the process of assisting an educator in the design and delivery of BL beneficial and apply similar approaches to deal with uncertainty about how to design an efficient and effective BL course for those who have a few experiences or no experience in teaching and designing BL.

The study employed a DBR method that required the researchers to iteratively practice designing, implementing, evaluating and redesigning the $\mathrm{BL}$ course to create the best learning environment. Instructional designers should not ignore the refinement of a learning environment at least one time after the initial implementation. For instance, discussion board activities are the primary activities that stimulate critical thinking on a topic or issue through the right questions (Picciano, 2009). However, discussion board activities didn't serve as its intended purpose because of the questions seeking only factual information. Refining the questions made a substantial change in the learning environment in which the students exchanged information among themselves and shared their own perspectives.

Instructional designers might use multiple design possibilities to transform educator-led learning into student-led learning. A variety of instructional activities, specifically Google Documents, and the course Blackboard site were utilized to increase student engagement, promote active and collaborative learning activities in this study. Discussions are a key factor to share knowledge and experiences among students in BL environments (Han, \& Ellis, 2019). However, instead of asking yes-no questions, it is important to ask slightly challenging or highly complex discussion questions that require students to exchange their ideas and share knowledge and experiences. Also, educators do not need to tie to Blackboard to create their own dynamic course sites. Instead, they have opportunities to create their own dynamic course sites by benefitting from free learning management systems (Gkemisi, Paraskeva, Alexiou and Bouta, 2016). The significant point was to take into account educator background, students' needs, attitudes and expectations, and course content when designing a learning environment where students became active knowledge seekers and choosing technological tools, resources and processes to support teaching and learning. Also, the basic and well-organized design of a learning environment was important to improve the quality of teaching and learning experiences. 


\section{CONCLUSION}

There is a lack of scientific investigation with the systematic implementation and development of a BL in terms of an inexperienced educator in teaching and designing a BL course in the current literature. The present study addressed this gap by assisting an inexperienced educator in teaching and designing a BL course by selecting suitable technological resources and processes to create the desired BL course, and determining the strengths and weaknesses of the educator to efficiently and effectively enhance the BL course via the iterative designed intervention phases. Therefore, the aim of the research was to decide what appropriate practices were needed to assist an educator who had no experience in designing and delivering BL to accomplish creating and implementing an efficient and effective BL and to document the educator's thoughts on the initial teaching experience of BL. According to the results, determining the particular goals of the course, the educator's prior experiences and availability of appropriate technological resources guided the lead researcher to assist the educator in the design, implementation and redesign processes of the BL course. BL allowed the educator to adopt active learning approaches, engage students in critical thinking and promote the quality of interactive and collaborative learning assignments by means of benefitting from Google Documents and Blackboard Learn (Learning Management System) as learning resources. It was the key consideration to provide online collaborative learning activities to have students share knowledge and experiences with peers. In this sense, they became active knowledge seekers who construct their own knowledge through the interaction and sense of engagement in a learning community in BL. Although the educator indicated the time limitation as an obstacle to teach more efficient BL course, the educator was contented with teaching and the designing BL course and found it useful and supportive overall. Although the study was conducted with a limited number of participants, the results are expected to contribute to insight for educators inexperienced in teaching and designing an efficient and effective BL course. It is also expected to contribute insight for instructional designers who consider the iterative refinement of a learning environment to design and deliver high-quality instructional products and experiences and to increase the awareness of the designers about the process of designing and implementing the desired BL course through iterative phases in a real-life context.

Authors' Note: This study was generated from a part of the first author's PhD dissertation. 


\title{
BIODATA and CONTACT ADDRESSES of AUTHORS
}

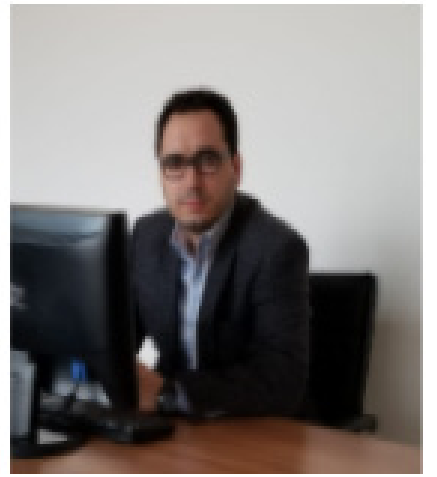

Dr. Ahmet Berk USTUN is an Assistant Professor of Computer Technology and Information Systems in the Faculty of Sciences at Bartin University. Dr. Ustun gained his Ph.D. in Learning Design and Technology at May, 2018. His academic interest areas are blended learning, online learning, emerging technologies, virtual reality, augmented reality, mixed reality and learning analytics. He has over 15 publications in the research and practice of instructional design including a book chapter and refereed journal articles. He has presented on a wide range of topics at national and international conferences.

\section{Ahmet Berk USTUN}

Computer Technology and Information Systems, Faculty of Sciences

Address: Bartin University, 74110, Bartin, TURKEY

Phone: +90 3785011000 ,

E-mail: ustun.ab@gmail.com

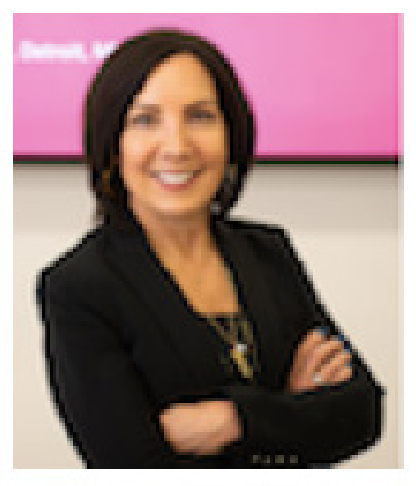

Dr. Monica Walsh TRACEY is a Professor of Learning Design and Technology in the College of Education at Wayne State University. Her teaching and research focuses on theory and design research of interdisciplinary design including developing designer professional identity, design thinking and empathic design. She has worked for over 35 years in design and on numerous design projects. Her work includes designing internationally and across disciplines. She has over 60 publications in the research and practice of instructional design including a Brown book award winning co-authored book, the Instructional Design Knowledge Base, numerous book chapters and refereed journal articles on design.

\author{
Monica Walsh TRACEY \\ Learning Design and Technology, College of Education \\ Address: Wayne State University, 48202, Detroit, Michigan, USA \\ Phone: +1 313-577-1700, \\ E-mail: MonicaTracey@wayne.edu
}




\section{REFERENCES}

Al-Ani, W. T. (2013). Blended learning approach using moodle and student's achievement at Sultan Qaboos University in Oman. Journal of Education and Learning, 2(3), 96. https://doi.org/10.5539/jel. v2n3p96

Azodi, N., \& Lotfi, A. (2020). E-Collaborative Tasks and the Enhancement of Writing Performance among Iranian University-Level EFL Learners. Turkish Online Journal of Distance Education, 21(1), 165180. https://doi.org/10.17718/tojde.690388

Baehr, C. (2012). Incorporating user appropriation, media richness, and collaborative knowledge sharing into blended e-learning training tutorial. IEEE Transactions on Professional Communication, 55(2), 175-184. https://doi.org/10.1109/TPC.2012.2190346

Baturay, M. H., \& Toker, S. (2019). The Comparison of Trust in Virtual and Face-To-Face Collaborative Learning Teams. Turkish Online Journal of Distance Education, 20(3), 153-164. https://doi. org/10.17718/tojde.601929

Bilgic, H. G., \& Tuzun, H. (2020). Issues and Challenges in Web-Based Distance Education Programs in Turkish Higher Education Institutes. Turkish Online Journal of Distance Education, 21(1), 143164. https://doi.org/10.17718/tojde.690385

Boelens, R., De Wever, B., \& Voet, M. (2017). Four key challenges to the design of blended learning: A systematic literature review. Educational Research Review, 22, 1-18. https://doi.org/10.1016/j. edurev.2017.06.001

Bonk, C. J., \& Graham, C. R. (2006). The handbook of blended learning: global perspectives, local designs. San Francisco, CA: Pfeiffer.

Bonk, C. J., Kim, K. J., \& Zeng, T. (2006). Future directions of blended learning in higher education and workplace learning settings. In Bonk, CJ \& Graham, CR: The Handbook of Blended Learning (pp. 550-567). San Francisco, CA: Pfeiffer Publishing.

Bradley, C., Erice, M., Halfer, D., Jordan, K., Lebaugh, D., Opperman, C., \& Stephen, J. (2007). The impact of a blended learning approach on instructor and learner satisfaction with preceptor education. Journal for Nurses in Staff Development, 23, 164-170. https://doi.org/10.1097/01. NND.0000281415.97106.41

Chickering, A. W., \& Gamson, Z. F. (1987). Seven principles for good practice in undergraduate education. AAHE bulletin, 3, 7.

Chou, A. Y., \& Chou, D. C. (2011). Course management systems and blended learning: An innovative learning approach. Decision Sciences Journal of Innovative Education, 9(3), 463-484. https://doi. org/10.1111/j.1540-4609.2011.00325.x

Creswell, J. W. (2007). Research design: Qualitative, quantitative, and mixed methods approaches (3rd ed.). Thousand Oaks, CA: Sage.

Deslauriers, L., Schelew, E., \& Wieman, C. (2011). Improved learning in a large-enrolment physics class. Science, 332, 862-864. https://doi.org/10.1126/science.1201783

Donnelly, R. (2010). Harmonizing technology with interaction in blended problem-based learning. Computers \& Education, 54(2), 350-359. https://doi.org/10.1016/j.compedu.2009.08.012

Gall, M.D., Borg, W.R., \& Gall, J.P. (1996). Educational research: An introduction. Longman Publishing.

Galvis, A. H. (2018). Supporting decision-making processes on blended learning in higher education: literature and good practices review. International Journal of Educational Technology in Higher Education, 15(1), 25. https://doi.org/10.1186/s41239-018-0106-1

Garrison, D. R., \& Kanuka, H. (2004). Blended learning: Uncovering its transformative potential in higher education. The Internet and Higher Education, 7(2), 95-105. https://doi.org/10.1016/j. iheduc.2004.02.001 
Garrison, D.R., \& Vaughan, N.D. (2007). Blended learning in higher education: Framework, principles, and guidelines. San Francisco, CA: Jossey-Bass.

Gay, L. R., Mills, G. E., \& Airasian, P. W. (2012). Educational research: Competencies for analysis and applications. Pearson Higher Ed.

Geng, S., Law, K. M., \& Niu, B. (2019). Investigating self-directed learning and technology readiness in blending learning environment. International Journal of Educational Technology in Higher Education, 16(1), 17. https://doi.org/10.1007/s10798-018-9462-3

George, D., \& Mallery, P. (2003). SPSS for Windows step by step: A simple guide and reference. 11.0 update (4th ed.). Boston: Allyn \& Bacon.

Gkemisi, S., Paraskeva, F., Alexiou, A., \& Bouta, H. (2016). Strengthening collaboration and communication skills in an online TPD program for 21st-century educators. International Journal of Learning Technology, 11(4), 340-363. https://doi.org/10.1504/IJLT.2016.081710

Glaser, B. G. (1965). The constant comparative method of qualitative analysis. Social problems, 12(4), 436445. https://doi.org/10.2307/798843

Graham, C. R. (2006). Blended learning systems: definition, current trends, and future directions. In Bonk, CJ \& Graham, CR (Eds.), The Handbook of Blended Learning (pp. 3-21). San Francisco, CA: Pfeiffer Publishing.

Graham, C. R. (2013). Emerging practice and research in blended learning. In M. G. Moore (Ed.), Handbook of distance education, (3rd ed., pp. 333-350). New York: Routledge.

Halverson, L. R., Graham, C. R., Spring, K. J., Drysdale, J. S., \& Henrie, C. R. (2014). A thematic analysis of the most highly cited scholarship in the first decade of blended learning research. The Internet and Higher Education, 20, 20-34. https://doi.org/10.1016/j.iheduc.2013.09.004

Han, F., \& Ellis, R. A. (2019). Identifying consistent patterns of quality learning discussions in blended learning. The Internet and Higher Education, 40, 12-19. https://doi.org/10.1016/j.iheduc.2018.09.002

Hew, K. F., \& Cheung, W. S. (2014). Introduction. In K. F. Hew \& W. S. Cheung (Eds.), Using blended learning: evidence-based practices (pp. 1-39). London: Springer.

Hoic-Bozic, N., Mornar, V., \& Boticki, I. (2009). A blended learning approach to course design and implementation. IEEE Transactions on Education, 52(1), 19-30. https://doi.org/10.1109/ TE.2007.914945

Hosseinpour, N., Biria, R., \& Rezvani, E. (2019). Promoting academic writing proficiency of Iranian EFL learners through blended learning. Turkish Online Journal of Distance Education, 20(4), 99-116. https://doi.org/10.17718/tojde.640525

Ibrahim, M. M., \& Nat, M. (2019). Blended learning motivation model for instructors in higher education institutions. International Journal of Educational Technology in Higher Education, 16(1), 12. https:// doi.org/10.1186/s41239-019-0145-2

Isiguzel, B. (2014). The blended learning environment on the foreign language learning process: A balance for motivation and achievement. Turkish Online Journal of Distance Education, 15(3), 108-121. https://doi.org/10.17718/tojde.41051

Jepchumba, L., \& Gaceri, P. (2013). "For us it was a learning experience": Design, development and implementation of blended learning. European Journal of Training and Development, 37(7), 615634. https://doi.org/10.1108/EJTD-10-2012-0052

Karaoglan Yilmaz, F.G. (2020). Modeling different variables in flipped classrooms supported with learning analytics feedback. Journal of Information and Communication Technologies, 1(2), 78-93.

Keller, J. M. (1987). Development and use of the ARCS Model of Instructional Design. Journal of Instructional Development, 10(3), 2-10. https://doi.org/10.1007/BF02905780

Keller, J. M. (2010). Motivational design for learning and performance: The ARCS model approach. Springer Science \& Business Media. 
Maza, E. M. T., Lozano, M. T. G., Alarcón, A. C. C., Zuluaga, L. M., \& Fadul, M. G. (2016). Blended learning supported by digital technology and competency-based medical education: a case study of the social medicine course at the Universidad de los Andes, Colombia. International Journal of Educational Technology in Higher Education, 13(1), 27. https://doi.org/10.1186/s41239-0160027-9

McKeachie, W. J., \& Svinicki, M. (2014). McKeachie's teaching tips: Strategies, research, and theory for college and university teachers (14th ed.). Belmont, CA : Wadsworth, Cengage Learning.

McKenney, S., \& Reeves, T. C. (2014). Educational design research. In Handbook of research on educational communications and technology (pp. 131-140). Springer New York.

Morse J. M. (1991) Strategies for sampling. In Qualitative Nursing According to Glaser (1978) Research: A Contemporary Dialogue (Morse J.M. ed.), Sage, Newbury Park, California, pp. 127-145.

Mozelius, P., \& Rydell, C, (2017). Problems affecting successful implementation of blended learning in higher education: The teacher perspective. International Journal of Information and Communication Technologies in Education, 6(1), 4-13. https://doi.org/10.1515/ijicte

Napier, N. P., Dekhane, S., \& Smith, S. (2011). Transitioning to blended learning: Understanding student and faculty perceptions. Journal of Asynchronous Learning Networks, 15(1), 20-32. 10.24059/olj. v15i1.188

Ocak, M. A. (2011). Why are faculty members not teaching blended courses? Insights from faculty members. Computers \& Education, 56(3), 689-699. https://doi.org/10.1016/j.compedu.2010.10.011

Osguthorpe, R. T., \& Graham, C.R. (2003). Blended learning environments: Definitions and directions. Quarterly Review of Distance Education, 4(3), 227-233. Retrieved January 13, 2020 from https:// www.learntechlib.org/p/97576/.

Patton, M. Q. (1990). Qualitative evaluation and research methods (2nd ed.). Newbury Park, CA: Sage Publications.

Picciano, A. G. (2009). Blending with purpose: The multimodal model. Journal of Asynchronous Learning Networks, 13(1), 7-18. https://doi.org/10.24059/olj.v13i1.1673

Picciano, A. G. (2013). Introduction to blended learning: research perspectives, volume 2. In Picciano, A. G., Dziuban, C. D., \& Graham, C. R. (Eds.), Blended learning: Research Perspectives (Vol. 2). Routledge.

Porter, W. W., \& Graham, C. R. (2016). Institutional drivers and barriers to faculty adoption of blended learning in higher education. British Journal of Educational Technology, 47(4), 748-762. https:// doi.org/10.1111/bjet.12269

Porter, W. W., Graham, C. R., Spring, K. A., \& Welch, K. R. (2014). Blended learning in higher education: Institutional adoption and implementation. Computers \& Education, 75, 185-195. https://doi. org/10.1016/j.compedu.2014.02.011

Reinholz, D.L. (2017). Design trees: providing roots for revision in design-based research. International Journal of Learning Technology, 12(4), 275-293. https://doi.org/10.1504/IJLT.2017.089907

Ruona, W.E.A. (2005). Analyzing Qualitative Data. In Swanson, R.A, \& Holton, E.F. (Eds.), Research in Organizations, Foundations and Methods of Inquiry (pp. 233-263). San Fransico: Berrett-Koehler Publishers, Inc.

Shand, K. \& Glassett Farrelly, S. (2017). Using blended teaching to teach blended learning: Lessons learned from pre-service teachers in an instructional methods course. Journal of Online Learning Research, 3(1), 5-30. Waynesville, NC USA: Association for the Advancement of Computing in Education (AACE). Retrieved March 1, 2020 from https://www.learntechlib.org/primary/p/172566/.

The Design-Based Research Collective. (2003). Design-based research: An emerging paradigm for educational inquiry. Educational Researcher, 32(1), 5-8. https://doi.org/10.3102/0013189X032001005 
Tongco, M.D.C. (2007). Purposive sampling as a tool for informant selection. Ethnobotany Research and Applications, 5, 147-158. Retrieved from http://ethnobotanyjournal.org/index.php/era/article/ view/126/111

Vanslambrouck, S., Zhu, C., Lombaerts, K., Philipsen, B., \& Tondeur, J. (2018). Students' motivation and subjective task value of participating in online and blended learning environments. The Internet and Higher Education, 36, 33-40. https://doi.org/10.1016/j.iheduc.2017.09.002

Wang, F., \& Hannafin, M. J. (2005). Design-based research and technology-enhanced learning environments. Educational Technology Research and Development, 53(4), 5-23. https://doi.org/10.1007/ BF02504682

Wu, J. H., Tennyson, R. D., \& Hsia, T. L. (2010). A study of student satisfaction in a blended e-learning system environment. Computers \& Education, 55, 155-164. https://doi.org/10.1016/j. compedu.2009.12.012

Yilmaz, R., Karaoglan Yilmaz, F. G., \& Kilic Cakmak, E. (2017). The impact of transactive memory system and interaction platform in collaborative knowledge construction on social presence and selfregulation. Interactive Learning Environments, 25(8), 949-969. https://doi.org/10.1080/104948 20.2016.1224905

Yilmaz, R. (2016). Knowledge sharing behaviors in e-learning community: Exploring the role of academic self-efficacy and sense of community. Computers in Human Behavior, 63, 373-382. https://doi. org/10.1016/j.chb.2016.05.055

Yurdakul, I. K. (2011). Examining technopedagogical knowledge competencies of preservice teachers based on ICT usage. Hacettepe University Journal of Education, 40, 397-408. https://doi.org/10.1016/j. sbspro.2015.01.648

Zioga, C., \& Bikos, K. (2020). Collaborative Writing Using Google Docs in Primary Education: Development of Argumentative Discourse. Turkish Online Journal of Distance Education, 21(1), 133-142. https://doi.org/10.17718/tojde.690372 